\title{
COVID-19 E VIDA IDOSA
}

\author{
COVID-19 AND ELDERLY LIFE
}

Paulo Rodrigues dos Santos ${ }^{1}$

\begin{abstract}
Resumo
O texto objetiva contribuir para a compreensão do por que da pandemia da SARS Cov 2 travar o mundo capitalista, com base em tríplice recorte: a) - delineamento da vulnerabilidade biológica da população mundial frente à pandemia, com ênfase na condição idosa, na descrição de um conjunto de afecções não transmissíveis, de predominância global e na desnaturalização do óbito, por Covid-19, na velhice; b) - análise da hipótese de que tais enfermidades resultam de racionalidades econômicas e políticas de base medicamentosa e alimentar, que conformam um tipo de governo populacional global, uma biopolítica da "saúde"; c) - descrição do campo medicinal compartido em: "medicina da doença", que atua com cerca de dois terços da população; "medicina da saúde", com ação sobre, aproximadamente, um terço da população. Ambas com condição legal constituem domínios econômicos financeiros da economia mundial, duas linhas da medicina oficial implicadas na saúde como negócio. $O$ texto articula metodologia quantitativa e qualitativa e tem suporte nas formulações teóricas de Michel Foucault.
\end{abstract}

Palavras chave: Biopolítica; Covid-19; Envelhecimento; Vulnerabilidade biológica.

\begin{abstract}
The text aims to contribute to the understanding of why the SARS Cov 2 pandemic stops the capitalist world, based on a triple cut: a) - delineation of the biological vulnerability of the world population in the face of the pandemic, with emphasis on the elderly condition, in the description of a set of non-communicable diseases, of global predominance and in the denaturalization of death, by Covid-19, in old age; b) - analysis of the hypothesis that such diseases result from economic and political rationalities based on medication and food, which form a type of global population government, a "health" biopolitics; c) - description of the medicinal field divided into: "disease medicine", which works with about two thirds of the population; "Health medicine", with action on approximately one third of the population. Both with legal status are financial economic domains of the world economy, two lines of official medicine involved in health as a business. The text articulates quantitative and qualitative methodology and is supported by Michel Foucault's theoretical formulations.
\end{abstract}

Keywords: Biopolitics; Covid-19; Aging; Biological vulnerability.

\footnotetext{
1 Doutor em Educação Brasileira pela Universidade Federal do Ceará. Professor na Universidade Estadual de Santa Cruz.

E-mail: santospros@yahoo.com.br
} 


\title{
1. Introdução
}

\begin{abstract}
"As epidemias acabam se resolvendo, sucumbindo à ação social ou esgotando o suprimento de vítimas suscetíveis." David S. Jones, MD, Ph.D. 12.05.2020.
\end{abstract}

A atual condição da população mundial pode ser vista como um terreno biológico favorável aos efeitos letais de ataques virais como se constata na atual pandemia da COVID-19. Esse é um aspecto pouco ou não problematizado, ou não abordado em vista a se compreender a pandemia naquilo que a torna mais assustadora, trágica, temerosa, geradora de "pânico funerário" e, portanto, capaz de fazer parar o Planeta.

Talvez, aquilo que faz a pandemia da Covid-19 ser o que é, sua capacidade de impactar a normalidade da vida social, de impor medo biológico, de criar descontinuidades nas regularidades da vida urbana, seu fazer "parar a Terra", por certo, não provem exclusivamente de uma diferença viral da própria natureza da SARS COV 2 , de alguma especificidade bioquímica que lhe seja própria, mas de dadas condições patológicas, de certo grau elevado de morbidade presente em expressivos contingentes das populações do planeta.

A questão mais imediata do colapso dos sistemas hospitalares, decorrente de políticas públicas antidemocráticas, justificou o isolamento social ou políticas de confinamento que, de fato, não explica a onda de "pânico funerário", crise de ansiedade, medo e pavor provocadas pela disseminação intensificada de informações midiáticas. Quem pode dizer para si mesmo da própria condição de saúde? Ou pensar que a saúde de suas crianças e idosos é segura frente à pandemia? A condição individual de saúde é interrogação. O sentimento de risco é lugar comum. O medo biológico, verdadeira onda de negatividade, cruza o Planeta. O patológico é histórico.

Pepe Escobar (2020) emite um enunciado pertinente a essas reflexões - "Bem, a história, na verdade, nos diz que as epidemias são momentos reveladores, mais do que transformadores sociais". Em sintonia com essa apercepção, talvez seja igualmente oportuno, produtivo e politicamente eficaz, não apenas exercitar a imaginação sociológica para perscrutar o que teremos ou seremos no pós-pandemia, como explorar aquilo que esse momento histórico, aquilo que o 
acontecimento COVID-19, permite fazer ver da atualidade. Diagnosticar o presente pode ser factível nas atuais circunstancias.

Por que a Covid-19 travou o capitalismo contemporâneo? Parte da resposta, a essa questão, tem relação com a vulnerabilidade mórbida de grandes segmentos populacionais de diferentes faixas etárias em escala global. A atual relação entre o normal e o patológico no campo populacional parece ter alçado um patamar estável, um gradiente médio, em que $20 \%$ a $30 \%$ ou mais da população mundial compõe o domínio patológico; mais adiante mostro os dados populacionais dessa condição que distribui-se em segmentos de classe, idade, gênero, cor, etnia, etc. Tal fragilidade biológica do meio social, com amplo espectro para inclusão no campo das possibilidades de morbimortalidade, tem implicações sobre o controle da condição e da conduta da população pelo sistema médico-farmacológico.

Como é próprio da história das pandemias, a SARS Cov 2 gera adoecimento de milhões de pessoas em todo o mundo. Não obstante, é preciso indagar sobre a efetividade desse processo, sua natureza, relações e proporções entre casos graves e leves, óbito e sobrevida, graus de letalidade do vírus em comparação com outros eventos virais; por em questão as taxas de mortalidade e suas relações com o fato, não problematizado, de milhões de pessoas no mundo estarem acometida das mesmas patologias, a exemplo das demências, cardiopatias, "diabesidade", hepatopatias, doenças pulmonares, dentre outras; e o fato, de comorbidade ser comum a grande parte dos casos considerados graves. Toda essa circunstância parece indicar que a população mundial é afetada pelos mesmos danos, da mesma forma, pelas mesmas causas e agentes por todo o planeta.

Para caracterizar esse quadro global, contingente, histórico, de vulnerabilidade biológica populacional e dar a ver a - o conjunto mundial de enfermidades - que perfaz essa condição trago dados de cinco enfermidades, classificáveis como pandêmicas, que afetam a imunologia da população mundial e respondem por uma significativa revelação da pandemia da Covid-19, a saber: o adoecimento populacional global, que esse texto objetiva apresentar como efeitos de uma biopolítica da saúde.

A crise global de múltiplas dimensões e determinantes, que emerge com a SARS Cov 2, configura um acontecimento que permite problematizar a verdade do discurso médico, epidemiológico, demográfico, farmacológico e midiático da 
"governamentalidade" global. Indagar, "(...) em torno do estatuto da verdade e do papel econômico-político que ela desempenha." (Foucault, 1979, p.11). Por em tela de juízo a verdade de práticas discursivas e não discursivas, enunciados, categorias, definições e orientações como as classificações das doenças sociais globais (diabetes, hipertensão, cardiopatias, obesidade, demências etc.) como "doenças hereditárias", "degenerativas", "crônicas-irreversíveis"; o exclusivo controle medicamentoso da pressão arterial; o exclusivo controle medicamentoso da insulina na diabete, prescrições alimentares para enfermos com produtos da indústria alimentar, prescrições de fármacos danosos e duvidosos, que dão sustentação a mecanismos de regularidade da condição biológica da população mundial.

Não constituiria um mecanismo de poder com tais características uma biopolítica? Isso é: uma forma de poder que tem por objeto não o indivíduo, mas a população e em que as intervenções ocorrem nos mecanismos biológicos da população (Foucault, 2008, p, 87). Uma biopolítica da doença diretamente atrelada a uma "medicina da doença"? Não uma "necropolítica", que se exerceria na dinâmica amigo - inimigo, mas uma biopolítica cuja materialização se dá pela expressão da morte cujo horizonte inclui no campo de possibilidades "cada um e a todos".

Esse texto tem suporte teórico nas formulações de Michel Foucault em medicina e governamentalidade. Objetiva, com base na análise dos efeitos do Covid19 sobre a população idosa, compreender as razões da vulnerabilidade biológica desse grupo, que parece resultar menos da condição senescente, que de uma trajetória de vida marcada pelo adoecimento social de formação lenta e duração longa.

O texto é constituído por essa introdução e mais quatro sessões. A segunda aborda o processo de envelhecimento/adoecimento e faz breve referência as teorias da Transição Demográfica e Transição Epidemiológica, que respaldam o discurso multilateral do campo da saúde; a terceira apresentar a configuração de enfermidades globais, que posiciono como doenças sociais, não transmissíveis, em oposição às doenças naturais, transmissíveis; a quarta as relações entre envelhecimento e o sistema imune; as considerações finais fecham o capítulo. 


\section{As doenças sociais globais e o envelhecimento}

Segundo Sophie Deram, (2018), a OMS define “(...) doenças crônicas, DC, como "doenças de longa duração e de progressão, geralmente, lenta", e o CDC, (Centers for Disease Prevention and Control), nos EUA, define-as como "condições que não curam, uma vez adquirida" (p.1). Apresenta ainda distinções entre DC, de dois tipos e duas especificidades: congênitas e não congênitas; transmissíveis e não transmissíveis. As DC congênitas são as que surgem no nascimento ou logo depois. As não congênitas, segundo Sophie Deram, (2018, p.1), “(...) o percurso dessas doenças é longo e muitas vezes o processo de cura é lento ou até inexistente, tornando uma condição permanente."

Classifico as DC transmissíveis, como doenças naturais e as DC não transmissíveis como doenças sociais. Enquanto as primeiras, a exemplo da AIDS e o Covid-19, dentre outras, são contraídas com base em patógenos infecciosos e parasitários, as segundas o são pela progressão de acometimentos fisiológicos, a exemplo das doenças metabólicas, como câncer e diabetes.

Marcadores de risco para o Covid-19 são todas essas patologias crônicas transmissíveis e não transmissíveis, incluída a obesidade. A questão que buscamos elucidar aqui, quanto a essas afecções, concerne à condição de comporem a classificação biopolítica de grupo de risco. Trago um posicionamento que conforma um segmento do campo discursivo quanto à natureza dessas patologias, minoritário e, em parte, em dissenso com o discurso medicinal, por acenar com a possiblidade de solução. Sophie Deram, (2018) conclui seu artigo sobre as doenças crônicas afirmando, depois de pontuar os marcadores de risco difundidos pela OMS, que: "(...) todos esses fatores de risco podem ser modificados (p.2)".

Observo que o enfoque com os marcadores de risco: estilo de vida, alimentação desequilibrada, sedentarismo, tabagismo, consumo de álcool, provém de agências multilaterais, como ONU e a OMS e tem ampla circulação no discurso medicinal implicando a responsabilização do sujeito pelo próprio adoecimento, ao tempo em que invisibiliza as dimensões decisivas da saúde populacional, isso é: a indústria alimentar, farmacêutica e a medicina da doença. Subentender que são as escolhas 
individuais as determinantes do adoecimento populacional é deixar à sombra a biopolítica da saúde contemporânea. Na mesma linha Zarcan Uronal (2020) afirma:

Em primeiro lugar não é verdade que adoecer e ter problemas de saúde tem a ver com a idade ou que não adianta fazer mais nada se você não se cuidou até agora. Isso é o que as pessoas doentes acreditam e que está impregnada na nossa sociedade, inclusive na classe médica (p.1).

O posicionamento de Deram, (2018), Uronal, (2020), Ribeiro, (2018) Mercola (2020), dentre outros, sobre as DCNTs enquadra-se no campo discursivo da medicina contemporânea na vertente minoritária; a vertente dominante responde efetivamente pela produção e circulação do saber medicinal.

Elegi como fator de diferenciação desse campo discursivo a afirmação ou negação da possibilidade de cura ou reversão das DCNTs. O segmento minoritário afirma a possibilidade de reversão e põe em tela de juízo a própria medicina e sua prática de medicação, posicionando-a como "medicina da doença" (Diwan, 2019; Javaheri, 2019, Ribeiro, 2018, Uronal, 2020, Mercola, 2020) e suas relações com a indústria farmacêutica como instância de fabricação/manutenção de doenças e com a indústria alimentar, na condição de fabricantes de produtos nocivos à saúde coletiva. O segmento oficial afirma a irreversibilidade das DCNTs e define DC como incurável.

\section{Envelhecimento populacional e as teorias da transição demográfica e da transição epidemiológica}

A Teoria da Transição Epidemiológica, TTE, foi formulada por Abdel Onram, (1971), com base na Teoria da Transição Demográfica, TTD, formulada, dentre outros demógrafos, por Frank Notestein, em 1944 (Teixeira e Alves, 2020). Os dois desenvolvem suas teorias com base na Europa e EUA. Posicionada como uma teoria epidemiológica da mudança populacional, a TTE tem um enfoque macro, com base na dinâmica populacional mundial e, junto com a TTD, dá suporte ao discurso multilateral de saúde, isto é: atuam como estratégias discursivas das agências multilaterais de saúde em suas intervenções de conduzir condutas discursivas e não discursivas. Os enunciados, definições, orientações, ações e programas em Saúde Pública oriundos dessas agências são formulados com base nessas teorias. 
A TTD pensa a dinâmica populacional com base em variáveis demográficas e a TTE trabalha a relação entre saúde e doença. Apontam invariavelmente para perfis de morbimortalidade diferenciados por indicadores sociais entre sociedades. São teorias evolucionistas (TEIXEIRA e ALVES, 2020), lineares, continuístas, etapista e, fortemente, dualistas. Precisam opor países desenvolvidos e subdesenvolvidos em suas tipificações. Quanto à natureza evolucionista Foucault (2002) esclarece que,

\begin{abstract}
No fundo, o evolucionismo [...] tornou-se, com toda naturalidade, em alguns anos do século XIX, não simplesmente uma maneira de transcrever em termos biológico o discurso político, não simplesmente uma maneira de ocultar um discurso político sob uma vestimenta científica, mas realmente a maneira de pensar as relações da colonização, a necessidade das guerras, a criminalidade, os fenômenos da loucura e da doença mental, a história da sociedade com suas diferentes classes etc. Em outras palavras, cada vez que houve enfrentamento, condenação à morte, luta, risco de morte, foi na forma do evolucionismo que se foi forçado, literalmente, a pensá-los. (P. 307).
\end{abstract}

\title{
4. Envelhecimento e imunidade
}

A pandemia da Covid-19 põe em evidência a questão imunológica.

Aconselhamentos para fortalecer a imunidade - do que fazer ao que não fazer - são amplamente disseminados em rede digitais por nutricionistas, You Tubers e Vloggers do campo da economia do Bem Estar. No enfrentamento ao coronavírus a condição imunológica é dita como decisiva e o eminente desenlace é uma possibilidade pressuposta para todos.

De fato, os pressupostos que incidem sobre as taxas de óbito não parecem contidas, no todo, na composição de grupos de risco, GR, que, na verdade, atuam na demarcação de nichos populacionais para controle de variações e medições de incidência e não na inteligibilidade epidemiológica. Isso pode ser observado na condição da imunidade individual em que expressões como imunodeprimidos, imunocomprometidos, imunodeficiência, imunossupressão, dentre outras, permitem compreender que a condição de risco concerne mais à condição imunológica que a idade ou qualquer outro marcador de risco. A condição de risco não é dada pelo pertencimento a Grs. Médicos morrem de Covid-19 não pela condição de profissionais de Saúde - um GR, mas com base em dadas condições imunológicas. 
O fato de a população idosa ser, no comum, afetada por desequilíbrios imunológicos, que as expressões apresentadas sinalizam, tem relação direta com a incidência de DCNTs nesse segmento. É certo que o óbito por Covid-19 tem mais relação com condição imunológica, à vulnerabilidade biológica do que a condição etária. Vale dizer que a morbimortalidade da população em geral e do segmento idoso em particular, por Covid-19, expressa o quadro de adoecimento constituído com regularidade ao longo da vida. Fazer de todo idoso "suscetível" a e provável sujeito de óbito por SRAS COV 2 é naturalizar a morte na velhice, fazer passar por natural a condição que resulta de intervenções históricas marcadamente atuais.

Esse fato tem importância na compreensão da diversidade das condições individuais, para além dos grupos de risco, presentes na incidência de óbitos e nas suas condições de possibilidade de ocorrência. Desnaturalizar a morte do idoso é buscar fazer ver a incidência de intervenções de poder não problematizadas, não visibilizadas e ganha relevância na medida em que a morbimortalidade na população idosa ganha certa visibilidade com a pandemia, tornando possível ver não a morte na velhice, mas a vida como espaço de inscrição de vulnerabilidade biológica que tem na velhice seu desenlace.

O envelhecimento imunocomprometido advém de trajetórias de vidas capturadas por patologias do contexto urbano capitalista, que na atualidade, a indústria alimentar e o complexo médico farmacêutico fazem incidir sobre a população mundial com amplitude e regularidade que demanda análise e enfrentamento. $A$ medicina da doença, a indústria farmacêutica, a indústria alimentar enquanto produtoras de DCNTs estão assentadas em que bases? O que sustenta essa racionalidade negativa?

Reconhecer que a Covid-19 é uma pandemia neoliberal, no sentido em que sua magnitude diz respeito a condições mundiais de empobrecimento populacional, a ausência ou a degradação dos sistemas públicos de saúde, ao perfil dos sistemas privados de saúde atrelados ao lucro; ao predomínio de segmentos desfavorecidos nas estatísticas de mortalidade, entre outros, não implica, necessariamente, que se tenha homogeneidade social frente à condição pandêmica. Vale dizer que não apenas grupos de risco e desfavorecidos estão circunscritos ao contexto ameaçado, mas que se trata mais do contexto que do patógeno. 
As desigualdades do acontecimento Covid-19 comportam múltiplas questões como a condição de saúde. Doenças sociais, como o câncer, o Alzheimer, as cardiopatias, dentre outras, que podem demandar até três décadas de formação e são diagnosticadas apenas quando se manifestam, podem servir como sinalizadores da condição imunológica de uma população num contexto como o atual.

No curso dessas doenças ocorrem graus variados de comprometimento imunológico. A condição de saúde e de vulnerabilidade biológica frente a surtos, epidemias ou pandemias parece maior do que os dados estabelecidos por afecções. Para um universo de centenas de milhões de pessoas com diabetes, ou qualquer outra das doenças crônicas, é válido considerar grandezas, com base em indivíduos com o mal em formação. Esse pressuposto é reforçado por Joseph Mercola (2020), que esclarece que nos EUA 30,3 milhões de pessoas têm diabetes e que 84 milhões estão na condição de pré-diabete. Contudo, antes da condição de pré-diabete ou de préhipertensão é presumível comprometimento de imunidade.

Essa é uma das razões, a meu ver, para a efetividade de inquietações, medos e "pânico funerário" para além das intervenções midiáticas. E mais ainda, talvez, para a aceitação, por grandes contingentes populacionais das políticas de isolamento social e de confinamento adotadas em muitos países. Antes de fechar essa seção trago dois pontos: a privação de sono, um fato comum à vida contemporânea e a letalidade da Covid 19. Quanto à privação de sono, Luciana Besedovsky et al, (2019), afirma que,

\footnotetext{
A deficiência crônica de sono perturba a homeostase imune, aumentando presumivelmente 0 risco de desenvolvimento e amplificação de várias doenças nas quais a desregulação imunológica é comum, por exemplo, doenças cardiovasculares, metabólicas, autoimunes e neurodegenerativas (p.60).
}

A letalidade da SARS COV 2 é um elemento a se considerar. Os altos índices de óbitos por Covid 19 são visto como evidência da alta letalidade do vírus. Não obstante, a letalidade da SARS COV 2 é baixa comparada as duas similares que assolaram o início do século XXI, da SARS COV 1, descoberto na cidade de Foshan, na China em 2002, e da Síndrome Respiratória do Oriente Médio, MERS, descoberta em 2012. Essas ocorrências foram analisadas por FAUCI, Anthony S. et al, que considera que, 
Se se presume que o número de casos assintomáticos ou minimamente sintomáticos é várias vezes maior que o número de casos relatados, a taxa de mortalidade de casos pode ser consideravelmente menor que $1 \%$. Isso sugere que as consequências clínicas gerais do Covid-19 podem ser mais semelhantes às de uma gripe sazonal grave (que tem uma taxa de mortalidade de aproximadamente $0,1 \%$ ) ou de uma pandemia (semelhante às de 1957 e 1968), em vez de uma doença semelhante à SARS ou MERS, que tiveram taxas de mortalidade de 9 a $10 \%$ e $36 \%$, respectivamente (p.1).

\section{Doenças sociais e vulnerabilidade biológica populacional}

As DCNTs têm forte prevalência na população mundial e respondem por $71 \%$ das 57 milhões de mortes anuais, 41 milhões de mortes em todo o mundo. A maioria em razão de quatro das principais dessas patologias: doenças cardiovascular, DCV, (cerca de 18 milhões, 44\% das mortes), câncer (com 9.0 milhões de mortes, 22\%), doenças crônicas respiratórias, DCR, (3,8 milhões de óbitos , 9\%), e diabetes (1,6 milhões, 4\%), (OMS, 2018).

Segundo o Ministério da Saúde, MS, (2018, p.2), no Brasil "As doenças crônicas não transmissíveis foram responsáveis por 56,9\% das mortes no Brasil no ano de 2017, na faixa etária de 30 a 69 anos e são consideradas um dos maiores problemas globais de saúde pública da atualidade".

Trata-se de doenças afins às condições de vida das sociedades capitalistas: cultura alimentar global, intervenções médico-farmacológicas e estilos de vida que incidem sobre a população mundial posicionada não como base demográfica de análises quantitativas, mas como forma biopolítica de governo, isso é, intervenções de poder que tomam a vida como objeto de interesse político (Foucault, 2008). $\mathrm{Na}$ continuidade apresento dados de algumas doenças sociais, duas delas marcadores de risco: obesidade e hipertensão arterial, que são vias para comorbidade com outras doenças metabólicas.

\section{Obesidade e covid-19}

A obesidade é um marcador de risco para a Covid-19. É um problema pandêmico; de predomínio urbano, que atinge variados grupos sociais. Implica índice de massa corpórea alta e obesidade abdominal, medida pela circunferência 


\title{
ISSN: 2675-682X \\ Dossiê Temático \\ COVID E INTERDISCIPLINARIDADE
}

da cintura. Contribui significativamente para comorbidade e mortalidade por todas as causas em relação ao peso normal (WANNMACHER, 2016).

O Instituto de Administração da Saúde e Assuntos Sociais, IP-RAM, uma agência pública portuguesa relata que,

\begin{abstract}
Segundo a Organização Mundial de Saúde (OMS), a obesidade, pandemia mundial do século XXI, mais do que duplicou desde 1980. Em 2014, mais de 1,9 biliões (39\%) de adultos tinha excesso de peso, 600 milhões $(13 \%)$ dos quais eram obesos. Mais preocupante ainda quando se observa que 41 milhões de crianças com idade inferior a cinco anos têm excesso de peso ou são obesas. Em Portugal, em 2014, segundo o Inquérito Nacional de Saúde, mais de metade da população portuguesa adulta $(52,8 \%)$ tinha excesso de peso e, de acordo com o Childhood Obesity Surveillance Initiative (COSI), $31,6 \%$ das crianças entre os 6 e os 8 anos tinham excesso de peso ou obesidade (p.1).
\end{abstract}

Dados da OMS, de 2018, indicam a cifra de 700 milhões de pessoas com obesidade e a estimativa, para 2025, de 2,3 bilhões de indivíduos com sobrepeso e 75 milhões de crianças com sobrepeso e obesidade (OMS, 2018). Os EUA, atualmente, é um dos países com mais pessoas com obesidade, com $36 \%$ de sua população nessa condição, enquanto no Brasil a obesidade afeta $19,9 \%$ da população (BRASIL/MS, 2019).

\section{A Hipertensão Arterial}

A hipertensão Arterial, HA, é outro importante marcador de risco da Covid 19 de características epidemiológicas e sociais semelhantes à obesidade. Segundo a Revista Brasileira de Hipertensão Arterial, RBHA, (2017, p. 12),

\begin{abstract}
Hipertensão arterial (HA) é condição clínica multifatorial caracterizada por elevação sustentada dos níveis pressóricos $\geq 140 \mathrm{e} / \mathrm{ou} 90 \mathrm{mmHg}$. Frequentemente se associa a distúrbios metabólicos, alterações funcionais e/ou estruturais de órgãos-alvo, sendo agravada pela presença de outros fatores de risco $(\mathrm{FR})$, como dislipidemia, obesidade abdominal, intolerância à glicose e diabetes melito (DM). Mantém associação independente com eventos como morte súbita, acidente vascular encefálico (AVE), infarto agudo do miocárdio (IAM), insuficiência cardíaca (IC), doença arterial periférica (DAP) e doença renal crônica (DRC), fatal e não fatal (p.12).
\end{abstract}

Ao considerar o impacto médico e social da hipertensão a RBHA, informa que nos EUA, em 2015, em 69\% de pacientes com primeiro episódio de IAM, 77\% 
de AVE e 60\% DAP. E que “(...) A HA é responsável por 45\% das mortes cardíacas e $51 \%$ das mortes decorrentes de AVE." (p.12). Quanto ao Brasil aponta a incidência e relação direta entre HA e doença cardiovascular, RBHA (2017):

No Brasil, HA atinge $32,5 \%$ (36 milhões) de indivíduos adultos, mais de $60 \%$ dos idosos, contribuindo direta ou indiretamente para $50 \%$ das mortes por doença cardiovascular (DCV). Junto com DM, suas complicações (cardíacas, renais e AVE) têm impacto elevado na perda da produtividade do trabalho e da renda familiar, estimada em US\$ 4,18 bilhões entre 2006 e 2015. Em 2013 ocorreram 1.138.670 óbitos, 339.672 dos quais $(29,8 \%)$ decorrentes de DCV, a principal causa de morte no País (p.12).

Semelhante à condição da diabetes, a hipertensão arterial implica uma fase intermediária de pré-hipertensão que amplia significativamente as estatísticas sobre a condição de HA, já que a pré-condição ainda não é registrada com frequência. Para a RBHA (2017),

\begin{abstract}
Pré-hipertensão (PH) é uma condição caracterizada por PA sistólica (PAS) entre 121 e 139 e/ou PA diastólica (PAD) entre 81 e $89 \mathrm{mmHg}$. A prevalência mundial variou de $21 \%$ a $37,7 \%$ em estudos de base populacional, com exceção do Irã (52,1\%). A PH associa-se a maior risco de desenvolvimento de HA e anormalidades cardíacas. Cerca de um terço dos eventos cardiovasculares (CV) atribuíveis à elevação de PA ocorrem em indivíduos com PH. Meta-análises do risco de incidência de DCV, DIC e AVE em indivíduos pré-hipertensos mostrou que o risco foi maior naqueles com níveis entre 130 e 139 ou 85 e $89 \mathrm{mmHg}$ do que naqueles com níveis entre 120 e 129 ou 80 e $84 \mathrm{mmHg}$ (p.14).
\end{abstract}

No mundo, os dados da OMS (2018) apontam a existência de 600 milhões de pessoas com HA, e a estimativa de crescimento de 60\% até 2025.

\title{
8. Diabetes
}

Como a maioria das DCNTs, a diabetes é insidiosa. Segundo o - Atlas de la diabetes 2019 - "A nível mundial, a diabetes é uma das dez principais causas de falecimento" (2019, p.10,) E avalia "(...) que mais de quatro milhões de pessoas entre 20 e 79 anos morreram por causa da diabetes em 2019" (2019, p.10, tradução do autor). Os seguintes dados são apresentados no Atlas da Diabetes, 2019: 
700 milhões em 2045. Dois terços das pessoas com diabetes vivem no meio urbano e três em cada quatro estão em idade ativa. A cada ano aumenta a quantidade de crianças e adolescentes (até os 19 anos de idade) com diabetes. Em 2019, há mais de um milhão de crianças e adolescentes com diabetes tipo 1. Calcula-se que 136 milhões de pessoas maiores de 65 anos têm diabetes e sua prevalência nesse grupo etário varia significativamente entre as regiões da FID (p.10).

Os dados sobre diabetes mostram predomínio no meio urbano de dois terços e menos de um terço de idosos maiores de 65 anos. Prevalência de pessoas ativas na ordem de três para quatro, o que permite pressupor a formação da enfermidade desde a infância e adolescência. As informações sobre incidência na infância e adolescência limitam-se a diabetes tipo 1 e não menciona a condição de pré-diabetes.

Mercola, (2020), faz referência a estimativa, em 2020, de 34 milhões de pessoas com diabetes (1 para cada 10) e 84 milhões (1 para 3) na condição de prédiabetes nos EUA, um total de 118 milhões nas duas condições, o que perfaz cerca de um terço da população do país. A associação Nacional de Diabetes estabelece a relação de 1 para 3 entre pessoas com diabete e pré-diabete. $O$ que permite calcular, para a população mundial de 463 milhões com diabete, o total de 1.389 .000 com prédiabete, cuja estimativa de manifestação da doença é de cinco anos. A soma entre a condição e a pré-condição eleva a cifra de pessoas em risco para a pandemia do Covid-19 próxima de 2 bilhões de pessoas no mundo.

\section{Casos de câncer}

Câncer é a segunda causa de mortes no mundo e razão de 9,6 milhões de óbitos em 2018, em que registrou-se 18,1 milhões de casos novos. Estima-se que uma em cada seis mortes têm relação com essa patologia. Países posicionados como de baixa renda são identificados com as populações mais vulneráveis ao câncer. Em 2017, apenas 26\% de países dessa condição dispunha de serviços públicos para essa DCNT (OPAS/Brasil, 2018).

Os tipos de mais comuns são: pulmão - 2,09 milhões de casos; mama - 2,09 milhões de casos; colorretal - 1,8 milhões de casos, próstata -1.28 milhões de casos; pele não-melanoma - 1,04 milhões de casos; estômago - 1,03 milhões de casos. Os registros de morte por câncer apontam: pulmão 1, 76 milhões de mortes; 
colorretal - 862 mil mortes; estômago - 783 mil mortes; fígado - 782 mil mortes; mama - 627 mil mortes (OPAS/Brasil, 2018).

No Brasil, segundo estimativa do INCA, (2020), para o ano de 2020, o total de casos de neoplasias será de 626.030, com 309.750 em homens e 316.030 em mulheres. A probabilidade de óbitos foi estimada em 224.712, com 117.477 masculinos e 107.235 femininos.

\section{Considerações finais}

Perto do início do milênio o economista Paul Zane Pilzer, (1999), publicou o vídeo - O Novo Trilhão - anunciando a emergência de um novo e lucrativo negócio, o Bem Estar, um setor econômico que, segundo previa, formaria os novos milionários do mundo. Ao analisar a sociedade norte-americana, esse autor, observou que:

(...) tive que descobrir o que chamamos de Negócio de Cuidados com a Saúde, que na realidade é a Indústria da Doença. Nossa indústria médica, hoje, tem muito pouco a ver, se muito, com saúde. Os $\$ 1,4$ trilhão que gastamos com cuidados médicos, que é um sétimo da economia dos EUA, diz respeito a ficar doente e lidar com os sintomas da doença (p.4).

E descreveu esse domínio, que ainda hoje se expande nos segmentos médios e altos das classes médias e da burguesia:

(...) defino "bem-estar" como dinheiro gasto para fazer você mesmo se sentir mais saudável, mesmo que você não esteja "doente" nos termos médicos comuns. Para ficar mais forte, mais saudável, ver melhor e ouvir melhor, para lutar contra o que chamamos de sintomas da idade (p.4).

Joseph Mercola é um dos médicos norte-americanos bem sucedidos do ramo Bem Estar e no seu site - portuguese.mercola.com - dispõe muitos artigos, E-books e serviços sobre esse tema. Ao pesquisar sua formação constatei que ele é um osteopata, formação em medicina, que afirma ser igual a dos MDs, Doutores em Medicina. E acredita que "(...) os MOs levam algo a mais à prática da medicina." (2020). E esclarece que:

Os médicos osteopatas praticam uma abordagem que trata da "pessoa inteira", tratando a pessoa como um todo em vez de apenas os seus sintomas. Com foco na saúde preventiva, os MOs ajudam os 
pacientes a desenvolver atitudes e estilos de vida que não só combatem as doenças, mas que também tentam prevenir elas (p. 3).

Temos que tanto a "Medicina da Doença" quanto a "Medicina da Saúde" são instâncias legais da medicina oficial. Enquanto a primeira tem sobre seus cuidados dois terços da população, a medicina do Bem Estar teria, como supôs Paul Pilzer:

\begin{abstract}
$38 \%$ da população dos EUA que não estão com sobrepeso compreendem 10 a 15 milhões de norte-americanos que estão envelhecendo; na medida e que isso acontece, eles estão ficando mais saudáveis, mais em forma e mais fortes - mais jovens por uma definição médica. Essas pessoas representam o novo setor econômico (p.5).
\end{abstract}

Esse economista descreveu para seu país, em 1999, as condições que hoje contribuem para a compreensão de uma dimensão da pandemia da Covid 19, o adoecimento de parte significativa da população mundial:

Hoje, a indústria da alimentação representa um trilhão de dólares anualmente; a indústria da doença responde por outro trilhão $(\$ 1,4$ trilhão na verdade). Essas duas indústrias se alimentam de uma forma muito insidiosa, porque uma grande parte das doenças de hoje é causada por má nutrição (5).

Frente a essa biopolítica que faz da saúde populacional objeto de interesses econômicos e políticos o envelhecimento populacional surge como desrazão, não como expressão de loucura, mas de racionalidades afins à barbárie.

A pandemia da COVID-19, ainda em curso no final de maio de 2020, com 5.175.925 casos e 338.084 óbitos, até 23.05.20 (MS, 2020), ao tempo em que impõe perdas de vida e sofrimento por todo o mundo, possibilita perspectivar a realidade desde o acontecimento, sua descontinuidade e diferença, que permite, naquilo que revela, por em questão verdades que obscurecem aspectos decisivos da vida, como o exemplo aqui analisado do processo de adoecimento da população mundial.

A condição enferma, de quase um bilhão de pessoas no mundo, cuja formação é lenta e a duração longa, uma vez diagnosticada, tem duração variada de indivíduo para indivíduo. Alguns com sobrevida de anos, outros de décadas. A vida, sua duração, é um mistério. A sobrevida frente ao adoecimento é arte médica. A vida idosa pertence ao complexo médico-farmacológico. Do ponto vista negocial, é dele que o Covid 19 as priva. 


\section{REFERÊNCIAS}

BESEDOVSKY, Luciana; LANGE, Tanja; HAACK, Monika. A interferência imune ao sono na saúde e na doença. Physiol. Rev, julho, 99 (3) 2019.

BRASIL/MS/INCA. Estatística de câncer. 2020, Disponível em: https://www.inca.gov.br/numeros-de-cancer Acesso em 26.05.2020.

. MS.SVS. Boletim Epidemiológico Especial COE COVID 19, N.17, 2020.

. Panorama da vigilância de doenças crônicas não transmissíveis no Brasil, 2018. Boletim Epidemiológico, Volume 50, № 40, Dez. 2019. Disponível em: https://www.saude.gov.br/images/pdf/2020/janeiro/16/Boletim-epidemiologico-SVS40-v2.pdf Acesso em 23.05.2020.

DAVID, S. J. História em crise: lições para Covid-19. NEJM. 2020. Disponível em: https://www.nejm.org/doi/full/10.1056/NEJMp2004361 ?query=featured coronavirus Acesso em: 18.05.2020.

ESCOBAR, Pepe. Controle de solo para o planeta quarentena: isto é apenas um teste. Disponível em: https://www.brasil247.com/blog/do-controle-de-solo-para-oplaneta-quarentena-isto-e-apenas-um-teste Acesso em 05.05.2020.

Foucault, Michel. Em defesa da sociedade. Curso no Collège de France, (19751976). São Paulo: Martins Fontes, 2002.

Verdade e poder. Entrevista com Alexandre Fontana. In: MACHADO, $\underline{\text { Roberto. A Microfísica do poder. Rio de Janeiro: Brasiliense, } 1979 .}$

Segurança, território e população. São Paulo: Martins Fontes, 2008.

FID. Atlas de la Diabetes de la FID. 2019. Disponível em: www.diabetesatlas.org Acesso em 18. 04.2020.

OPAS. Folha informativa: Câncer. 2018. Disponível em: https://www.paho.org/bra/index.php?option=com content\&view=article\&id=5588:folh a-informativa-cancer\&Itemid=1094 Acesso em 26.05.2020.

. Doenças Cardiovasculares. Disponível em:

https://www.paho.org/bra/index.php?option=com content\&view=article\&id=5253:doe ncas-cardiovasculares\&ltemid=1096 Acesso em 23.05.2020.

Portugal/lasaude. Obesidade: Pandemia Mundial do Século XXI. S/D. Disponível em: http://www.iasaude.pt/index.php/informacao-documentacao/recortes-deimprensa/1250-obesidade-pandemia-mundial-do-seculo-xxi Acesso em 26.05.2020. DERAM, Sophie. Doenças crônicas. https://www.sophiederam.com/br/bemestar/quais-sao-doencas-cronicas/ 
FAUCI, Anthony S.; LANE, H. Clifford; REDFIELD, Robert R. Covid-19 - Navigating the Uncharted. NEJM. Org. Editor's Note, 2020. Disponível em: https://www.nejm.org/doi/full/10.1056/NEJMe2002387 Acesso em: 20.05.2020.

JAVAHERI, Ali, DIWAN, Abhinav. Não aos lisossomos: um sinal para a resistência à insulina na obesidade. Cell Mol Gastroenterol Hepatol. 2019; 8 (1): 153-154. Disponível em: https://www.ncbi.nlm.nih.gov/pmc/articles/PMC6599106/ Acesso em: 20.03.20

MERCOLA, Joseph. Jejum intermitente em vez de insulina para diabetes tipo 2. 2020. Disponível em: https://portuguese.mercola.com/sites/articles/archive/2020/05/19/0jejum-e-apropriado-para-diabeticos.aspx Acesso em 25.05.2020.

ONRAM, Abdel. The Epidemiologic Transition: A Theory of the Epidemiology of Population Change.

PILZER, Paul Zane. O próximo trilhão. Network Marketing Lifestyles Magazine Aug. 2001.

POAS. Folha informativa - COVID-19. Disponível em https://www.paho.org/bra/index.php?option=com content\&view=article\&id=6101:covi d19\&Itemid=875 Acesso em 24.05.2020.

RIBEIRO, Lair. $O$ grande livro da saúde natural: 73 segredos da cura sem remédios. São Paulo: Jolivi, 2018.

SBH. 7 Diretrizes brasileiras Hipertensão Arterial. Rio de janeiro: RBHA, 2017; VOL.24(1):12-7

URONAL, Zarcan. Dr. Uronal Zancan, contato@uronalzancan.com 26.03.2020.

TEIXEIRA, Luiz e ALVES, Luiz. Ciência, saúde e doenças emergentes: uma história sem fim. Agência FioCruz, 2020.

THOMAS, Jane de Lima. A pandemia como professor: forçando os médicos a habitar a experiência de doenças graves. NEJM. Org. 20.05.2020. Disponível em:

https://www.nejm.org/doi/full/10.1056/NEJMp2015024?query=recirc top ribbon artic le 1 Acesso em 21.05.2020.

WANNMACHER, Lenita. Obesidade como fator de risco para morbidade e mortalidade: evidências sobre o manejo com medidas não medicamentosas. OPASIOMS. Vol. 1, № 7 Brasília, maio de 2016.

WHO. World health statistics 2018: monitoring health for the SDGs, sustainable development goals. Disponível em:

https://apps.who.int/iris/bitstream/handle/10665/272596/9789241565585eng.pdf?ua=1 
Manuscrito recebido em: 18 de dezembro de 2020

Aprovado em: 30 de dezembro de 2020

Publicado em: 30 de dezembro de 2020 